\title{
Eixos temáticos na comunicação entre profissionais da saúde e gestantes com HIV: revisão integrativa
}

Thematic axes in communication between health professionals and pregnant women with HIV: an integrative review

Ejes temáticos en la comunicación entre profesionales de la salud y gestantes con VIH: una revisión integradora

Recebido: 02/08/2021 | Revisado: 09/08/2021 | Aceito: 17/08/2021 | Publicado: 19/08/2021

Jéssica Fernanda Marcelina Fernandes Ferreira
ORCID: https://orcid.org/0000-0003-4382-941X
Universidade Federal do Triângulo Mineiro, Brasil
E-mail: jefmff@ gmail.com
Verônica Borges Kappel
ORCID: https://orcid.org/0000-0002-6932-9977
Universidade Federal do Triângulo Mineiro, Brasil
E-mail: veronica.kappel@ uftm.edu.br
Kéllen Campos Castro Moreira
ORCID: https://orcid.org/0000-0002-5288-4667
Universidade Federal do Triângulo Mineiro, Brasil
E-mail: kellen_camposcastro@yahoo.com.br
Larissa Cândida Melo
ORCID: https://orcid.org/0000-0001-6862-300X
Hospital João XXIII, Brasil
E-mail: larissa-cmelo@ @otmail.com
Pedro César Condeles
PRCID: https://orcid.org/0000-0001-6832-638X
E-mail: pedrocondeles@yahoo.com.br
Bibiane Dias Miranda Parreira
Universidade Federal do Triânulo Mineiro, Brasil
ORCID: https://orcid.org/0000-0002-5288-4667
Universidade Federal do Triângulo Mineiro, Brasil
E-mail: bibiane.parreira@ uftm.edu.br
Mariana Torreglosa Ruiz
ORCID:
Oniversidade Federal do Triângulo Mineiro, Brasil
E-mail: bethaniagoulart@yahoo.com.br

\section{Resumo}

Este artigo tem por objetivo identificar e descrever os principais eixos temáticos explorados pelos profissionais da saúde no campo da comunicação envolvendo gestantes com HIV. Trata-se de uma revisão integrativa, com amostra de cinco artigos primários selecionados no portal PubMed/Medline, nas bases eletrônicas LILACS, EMBASE e CINAHL, em 10 de dezembro de 2020, utilizando descritores indexados no Descritores em Ciências da Saúde. A questão norteadora foi: "Quais as evidências disponíveis na literatura a respeito da comunicação entre profissionais de saúde e gestantes com o Vírus da Imunodeficiência Humana, na assistência pré-natal?”. Critérios de inclusão: temática focada na comunicação de profissionais de saúde junto à gestante com o Vírus da Imunodeficiência Humana, durante a assistência pré-natal, nos idiomas português, espanhol ou inglês, sem recorte temporal. Critérios de exclusão: estudos de revisão, editoriais, carta-resposta, comentários e opiniões de especialistas, redigidos em idiomas diferentes de inglês, espanhol e português. Dentre os artigos encontrados em inglês, a maioria foi produzida na África do Sul. Identificaram-se dois estudos transversais, um qualitativo, um coorte observacional e um intervenção prospectiva quase experimental. Resultados são apresentados em quadro sinóptico com as principais informações. Constatou-se que a comunicação entre profissionais de saúde e gestantes com o Vírus da Imunodeficiência Humana possui dimensão complexa, interfere desde a adesão ao tratamento até a aceitação do diagnóstico. Todos os artigos revelaram impacto positivo dessa comunicação, colaborando, inclusive, na comunicação gestante-parceiro. A 
adequada comunicação viabiliza cuidado integral, possibilita vivenciar a gestação com maior plenitude e segurança, favorecendo para escolhas seguras e para o empoderamento feminino.

Palavras-chave: Gravidez; Comunicação em saúde; HIV; Cuidado pré-natal; Revisão.

\begin{abstract}
This article aims to identify and describe the main thematic axes explored by health professionals in the field of communication involving pregnant women with HIV. This is an integrative review, with a sample of six primary articles selected on the PubMed/Medline portal, in the LILACS, EMBASE and CINAHL electronic databases, on December 10, 2020, using descriptors indexed in Health Sciences Descriptors. The guiding question was: "What evidence is available in the literature regarding communication between health professionals and pregnant women with the Human Immunodeficiency Virus, in prenatal care?". Inclusion criteria: theme focused on communication between health professionals and pregnant women with the Human Immunodeficiency Virus, during prenatal care, in Portuguese, Spanish or English, without a time frame. Exclusion criteria: review studies, editorials, reply letters, comments and expert opinions, written in languages other than English, Spanish and Portuguese.Among the articles found in English, most were produced in South Africa. A qualitative study, two cross-sectional, an observational cohort and a prospective quasi-experimental intervention were identified. Results are presented in a synoptic table with the main information. It was found that communication between health professionals and pregnant women with the Human Immunodeficiency Virus has a complex dimension, interfering from treatment adherence to diagnosis acceptance. All articles revealed a positive impact of this communication, collaborating even in the pregnant-partner communication. Adequate communication enables comprehensive care, makes it possible to experience pregnancy with greater fullness and safety, favoring safe choices and female empowerment.
\end{abstract}

Keywords: Pregnancy; Health communication; HIV; Prenatal care; Review.

\begin{abstract}
Resumen
Este artículo tiene como objetivo identificar y describir los principales ejes temáticos explorados por los profesionales de la salud en el campo de la comunicación que involucra a mujeres embarazadas con VIH. Se trata de una revisión integradora, con una muestra de cinco artículos primarios seleccionados en el portal PubMed / Medline, en las bases de datos electrónicas LILACS, EMBASE y CINAHL, el 10 de diciembre de 2020, utilizando descriptores indexados en Health Sciences Descriptors. La pregunta orientadora fue: "¿Qué evidencia se encuentra disponible en la literatura sobre la comunicación entre profesionales de la salud y gestantes con el Virus de la Inmunodeficiencia Humana, en la atención prenatal?". Criterios de inclusión: tema centrado en la comunicación entre profesionales de la salud y gestantes con el Virus de la Inmunodeficiencia Humana, durante la atención prenatal, en portugués, español o inglés, sin marco temporal. Criterios de exclusión: estudios de revisión, editoriales, cartas de respuesta, comentarios y opiniones de expertos, redactados en idiomas distintos al inglés, español y portugués. Entre los artículos encontrados en inglés, la mayoría fueron producidos en Sudáfrica, identificándose un estudio cualitativo, dos transversales, una cohorte observacional y una intervención prospectiva cuasiexperimental. Los resultados se presentan en una tabla sinóptica con la información principal. Se encontró que la comunicación entre profesionales de la salud y gestantes con el Virus de Inmunodeficiencia Humana tiene una dimensión compleja, interfiriendo desde la adherencia al tratamiento hasta la aceptación del diagnóstico. Todos los artículos revelaron un impacto positivo de esta comunicación, colaborando incluso en la comunicación embarazada-pareja. Una adecuada comunicación posibilita una atención integral, posibilita vivir el embarazo con mayor plenitud y seguridad, favoreciendo la elección segura y el empoderamiento de la mujer.
\end{abstract}

Palabras clave: Embarazo; Comunicación en salud; VIH; Atención prenatal; Revisión.

\title{
1. Introdução
}

No início da epidemia do Vírus da Imunodeficiência Humana (HIV) e da Síndrome da Imunodeficiência Adquirida (Aids), havia predomínio de notificações de casos em homens. Entretanto, com o passar dos anos, a taxa de infecção na população feminina aumentou significativamente. Este aumento impactou diretamente na elevação do número de crianças contaminadas por meio da transmissão vertical (TV), que é a principal via de contágio até os 12 anos 11 meses e 29 dias de idade (Pontes et al., 2020).

Dados da Organização Mundial de Saúde (OMS) (World Health Organization, 2021) apontaram que até o final de 2019, cerca de 38 milhões de pessoas no mundo estariam vivendo com HIV; 67\% teriam acesso ao Antirretroviral (ARV) e ainda mais de sete milhões viveriam com o vírus, mas não teriam conhecimento do diagnóstico. Quanto à TV, não é possível totalizar os casos no mundo, pois este dado se apresenta subnotificado em muitos países. Porém, nota-se tendência crescente ou estável nestes índices nos países informantes (World Health Organization, 2021). 
Entre 2000 e 2020 houve notificação de 134.328 casos de gestantes infectadas pelo HIV, no Brasil. Desde 2010 aumentaram $21,7 \%$ dos casos, o que pode ser devido à testagem durante o pré-natal, sendo a taxa de infecção de 2,8 para cada 1000 nascidos vivos (Brasil, 2020). De acordo com os dados do Departamento de Informática do Sistema Único de Saúde (DATASUS), somente no ano de 2019, foram notificados 418 casos de Aids em crianças no Brasil, cuja transmissão ocorreu por via vertical. Desde 1985, foram notificados 17.910 casos de transmissão vertical do HIV no Brasil, o que evidência leve declínio ao longo dos anos e apresenta-se, atualmente, em fase de estabilização destes índices (Brasil, 2021).

No que se refere à TV, sabe-se que a gravidez é um momento singular na vida da mulher, pois ocorrem muitas mudanças biológicas, psicológicas e sociais, além da grande preocupação materna em gerar um bebê saudável. Isso tudo é intensificado quando a gestante vivencia o HIV, uma vez que a doença envolve, muitas vezes, conflitos pessoais, familiares, sentimentos de medo e insegurança, principalmente, quando se descobre o diagnóstico tardiamente, durante a triagem pré-natal (Trindade et al., 2021). Dessa forma, a mulher descobre concomitantemente, o diagnóstico da infecção e da gestação.

A equipe multiprofissional que atua na assistência pré-natal e, mais especificamente, o enfermeiro que participa ativamente das consultas, possui papel crucial na orientação dessa gestante quanto ao uso contínuo do ARV materna nos casos indicados, à necessidade de inibição da lactação após o parto e aos cuidados com o recém-nascido. A maneira como esse profissional de saúde conduzirá os diálogos junto à gestante terá consequências diretas na adesão dela aos tratamentos e retorno às próximas consultas de pré-natal (Trindade et al., 2021).

Uma comunicação baseada na empatia e respeito possui influência direta na adesão ou não ao tratamento dessa gestante. Todo paciente necessita sentir-se apoiado pela equipe de saúde, que pode fazer do momento de atendimento e acolhimento um espaço de escuta dos seus medos, angústias, e demais emoções, fornecendo-lhe o suporte de que necessita sem qualquer preconceito. Por isso, é importante que o profissional tenha um bom preparo, pois a maneira como a comunicação acontecer proporcionará criação de um vínculo efetivo e de confiança entre eles (Lobo et al., 2019).

A importância deste estudo fundamenta-se no fato de que a população de gestantes que vivem com HIV, representarem um grupo vulnerável, sendo assim, imprescindível que haja uma comunicação efetiva entre os profissionais de saúde e essas mulheres, para garantir o acolhimento humanizado e maior adesão ao tratamento. Esta pesquisa evidencia a síntese do conhecimento a respeito da comunicação de profissionais de saúde junto a gestantes com HIV, durante a assistência pré-natal e poderá contribuir para o entendimento sobre o estado da arte relacionada à temática, possibilitar a identificação de lacunas nas práticas profissionais, além de elucidar potencialidades a serem seguidas e disseminadas, fatores que justificam sua realização.

Este estudo tem por objetivo identificar e descrever os principais eixos temáticos explorados pelos profissionais de saúde no campo da comunicação envolvendo gestantes com HIV.

\section{Metodologia}

Trata-se de revisão integrativa, cujo objetivo é investigar um assunto, através da avaliação crítica, leitura e síntese de evidências sobre a temática na literatura existente (Sousa et al., 2017), realizada para responder à questão norteadora: "Quais os principais eixos temáticos explorados pelos profissionais da saúde no campo da comunicação envolvendo gestantes com HIV?".

Para elaboração da questão, utilizou-se a estratégia PCC, na qual P (Population) refere-se aos profissionais de saúde; $\mathrm{C}$ (Concept) diz respeito à comunicação e C (Context) está ligado à assistência pré-natal da gestação de mulheres com HIV.

A coleta dos dados ocorreu em 10 de dezembro de 2020 e as buscas foram realizadas nas bases de dados eletrônicas US National Library of Medicine National Institutes of Health (PubMed/Medline), Literatura Latino-Americana e do Caribe 
em Ciências da Saúde (LILACS), Excerpta Medica dataBASE (Embase) e Cumulative Index to Nursing and Allied Health Literature (CINAHL). A escolha das bases de dados apoiou-se no quantitativo de indexação de artigos primários da área da saúde. A leitura de títulos, resumos e descritores possibilitaram a seleção dos estudos para a revisão.

As buscas foram realizadas de forma independente por dois revisores, sendo um portador de título de doutor, e o outro, graduando em Enfermagem, em caso de diversidade um terceiro revisor portador de título de doutor também foi consultado, por meio dos descritores controlados do Medical Subject Headings (MeSH), do Cumulative Index to Nursing and Allied (CINAHL) Headings e do Descritores em Ciências da Saúde (DeCS), com os termos: "Pregnancy", "Health Communication", "HIV" e "Prenatal Care".

Utilizou-se a seguinte estratégia de busca evidenciada No Quadro 1:

Quadro 1 - Estratégia de busca. Uberaba, Minas Gerais, 2021.

\begin{tabular}{|c|c|c|}
\hline CINAHL & Descritores em Ciências da Saúde (DeSC) & Medline/PubMed \\
\hline $\begin{array}{l}\text { Pregnancy OR (Pregnancies) OR } \\
\text { Gestation AND Health Communication } \\
\text { OR Communication, Health OR } \\
\text { Communications, Health OR Health } \\
\text { Communications AND HIV OR } \\
\text { Human Immunodeficiency Virus OR } \\
\text { Immunodeficiency Virus, Human OR } \\
\text { Immunodeficiency Viruses, Human OR } \\
\text { Virus, Human Immunodeficiency OR } \\
\text { Viruses, Human Immunodeficiency OR } \\
\text { Human Immunodeficiency Viruses OR } \\
\text { Human T Cell Lymphotropic Virus } \\
\text { Type III OR Human T-Cell } \\
\text { Lymphotropic Virus Type III OR } \\
\text { Human T-Cell Leukemia Virus Type III } \\
\text { OR Human T Cell Leukemia Virus } \\
\text { Type III OR LAV-HTLV-III OR } \\
\text { Lymphadenopathy-Associated Virus } \\
\text { OR Lymphadenopathy Associated } \\
\text { Virus OR Lymphadenopathy- } \\
\text { Associated Viruses OR Virus, } \\
\text { Lymphadenopathy-Associated OR OR } \\
\text { Viruses, Lymphadenopathy-Associated } \\
\text { OR Human T Lymphotropic Virus } \\
\text { Type III OR Human T-Lymphotropic } \\
\text { Virus Type III OR AIDS Virus OR } \\
\text { AIDS Viruses OR Virus, AIDS OR } \\
\text { Viruses, AIDS OR Acquired Immune } \\
\text { Deficiency Syndrome Virus OR } \\
\text { Acquired Immunodeficiency Syndrome } \\
\text { Virus OR HTLV-III AND Prenatal } \\
\text { Care OR Care, Prenatal OR Antenatal } \\
\text { Care OR Care, Antenatal }\end{array}$ & 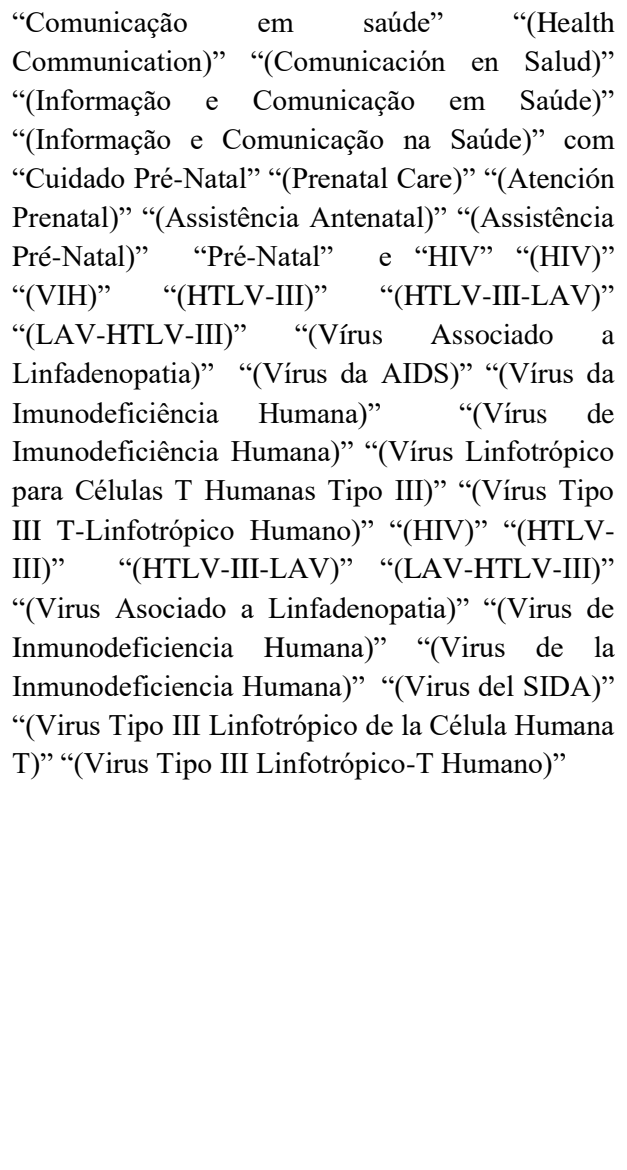 & $\begin{array}{l}\text { (pregnancy [MeSH Terms] OR pregnancies } \\
\text { OR gestation) AND (health communication } \\
\text { [MESH Terms] OR communication, health } \\
\text { OR communications, health OR health } \\
\text { communications) AND (HIV [MeSH } \\
\text { Terms] OR Human Immunodeficiency Virus } \\
\text { OR Immunodeficiency Virus, Human OR } \\
\text { Immunodeficiency Viruses, Human OR } \\
\text { Virus, Human Immunodeficiency OR } \\
\text { Viruses, Human Immunodeficiency OR } \\
\text { Human Immunodeficiency Viruses OR } \\
\text { Human T Cell Lymphotropic Virus Type III } \\
\text { OR Human T-Cell Lymphotropic Virus } \\
\text { Type III OR Human T-Cell Leukemia Virus } \\
\text { Type III OR Human T Cell Leukemia Virus } \\
\text { Type III OR LAV-HTLV-III OR } \\
\text { Lymphadenopathy-Associated Virus OR } \\
\text { Lymphadenopathy Associated Virus OR } \\
\text { Lymphadenopathy-Associated Viruses OR } \\
\text { Virus, Lymphadenopathy-Associated OR } \\
\text { Viruses, Lymphadenopathy-Associated OR } \\
\text { Human T Lymphotropic Virus Type III OR } \\
\text { Human T-Lymphotropic Virus Type III OR } \\
\text { AIDS Virus OR AIDS Viruses OR Virus, } \\
\text { AIDS OR Viruses, AIDS OR Acquired } \\
\text { Immune Deficiency Syndrome Virus OR } \\
\text { Acquired Immunodeficiency Syndrome } \\
\text { Virus OR HTLV-III) AND (prenatal care } \\
\text { [MeSH Terms] OR care, prenatal OR } \\
\text { antenatal care OR care, antenatal). }\end{array}$ \\
\hline
\end{tabular}

Fonte: Autores.

Os critérios de inclusão adotados foram: estudos sobre a temática focados na comunicação de profissionais de saúde junto à gestante com HIV, durante a assistência pré-natal, nos idiomas português, espanhol ou inglês, sem recorte temporal.

Foram excluídos: estudos de revisão, editoriais, carta-resposta, comentários e opiniões de especialistas, redigidos em idiomas diferentes de inglês, espanhol e português. Dessa forma, identificaram-se 152 artigos nas quatro bases de dados. O fluxograma Principais Itens para Relatar Revisões Sistemáticas e Meta- Análises (PRISMA) foi adotado para sistematizar o processo de inclusão dos estudos (Moher et al., 2009) apresentado na Figura 1. 
Figura 1 - Fluxograma do processo de busca dos dados, segundo o PRISMA. Uberaba, Minas Gerais, 2021.
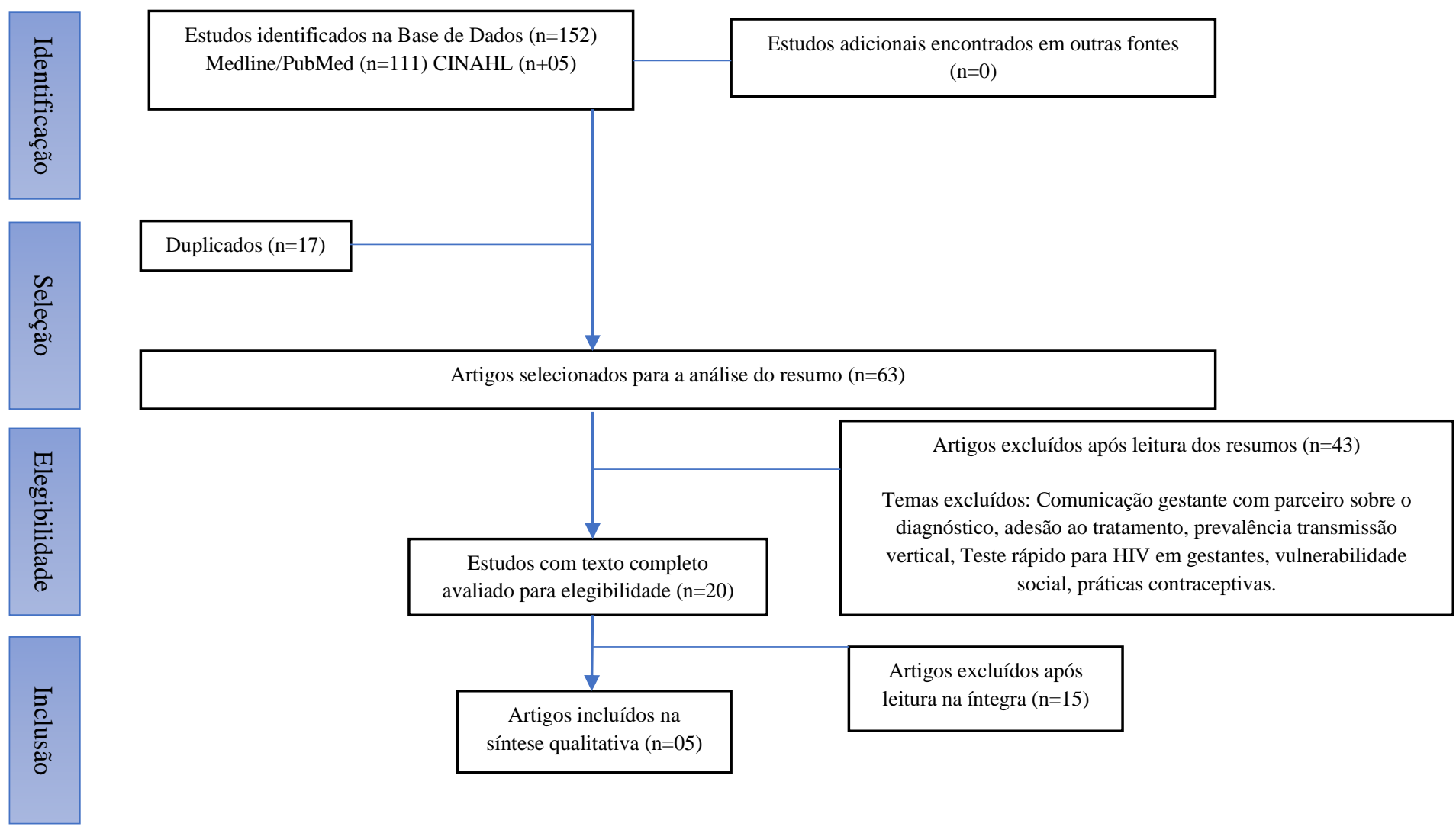

Fonte: Autores (2021).

Inicialmente, para fazer a seleção dos artigos, procedeu-se à análise do título e resumo e, dentre os selecionados, realizou-se uma nova leitura na íntegra para seleção final, resultando na amostra de cinco estudos. Foram excluídos da análise: 17 artigos que estavam duplicados nas bases de dados (repetidos); quatro devido à publicação em outros idiomas; seis por se tratarem de artigos de revisão da literatura, três editoriais/opinião de especialista e 116 por não responderem à questão norteadora do estudo.

Para o detalhamento das informações coletadas dos artigos, utilizou-se um instrumento, baseado nas diretrizes do Joanna Briggs Institute (Joanna Briggs Institute, 2014) contendo: identificação do artigo original (título, país produtor, ano de publicação); objetivo (s); amostra e delineamento; principais resultados e conclusões.

\section{Resultados e Discussão}

Conforme apresentado no Quadro 2, foram incluídos na revisão cinco artigos (Lemly et al., 2007; Lumbantoruan et al., 2020; Medina-Marino et al., 2020; Robb et al., 2018; Sarnquist et al., 2014), todos publicados em inglês, produzidos no período de 2007 a 2020. A maioria dos estudos foi produzida na África do Sul (60\%), sendo um deles em parceria com os Estados Unidos (20\%), um na França (20\%) e um na Indonésia (20\%). Nos estudos analisados, utilizaram-se métodos qualitativo (um estudo - 20\%); transversal (dois estudos - 40\%); coorte observacional (um estudo - 20\%) e um estudo de intervenção prospectiva quase experimental (um estudo - 20\%). 
Research, Society and Development, v. 10, n. 10, e574101019003, 2021

(CC BY 4.0) | ISSN 2525-3409 | DOI: http://dx.doi.org/10.33448/rsd-v10i10.19003

Quadro 2 - Sumarização das informações dos artigos selecionados. Uberaba, Minas Gerais, 2021.

\begin{tabular}{|c|c|c|c|c|c|c|}
\hline Título & País, Ano & Objetivos & Amostra & Delineamento & Principais Resultados & Conclusão \\
\hline $\begin{array}{l}\text { Integrating family } \\
\text { planning and prevention of } \\
\text { mother to child HIV } \\
\text { transmission in Zimbabwe } \\
\text { (Sarnquist et al., 2014) }\end{array}$ & $\begin{array}{l}\text { Zimbabue } \\
\text { (África do } \\
\text { Sul), } \\
2014\end{array}$ & \begin{tabular}{lr} 
Avaliar & a \\
viabilidade & $\mathrm{e}$ \\
eficácia & de \\
integrar & um \\
programa & de \\
planejamento & \\
familiar & ao \\
serviço & de \\
redução & da \\
transmissão & \\
\multicolumn{2}{l}{ vertical do HIV }
\end{tabular} & $\begin{array}{l}98 \\
\text { gestantes } \\
\text { com com } \\
\text { HIV }\end{array}$ & $\begin{array}{l}\text { Estudo de } \\
\text { intervenção } \\
\text { prospectivo } \\
\text { quase } \\
\text { experimental }\end{array}$ & $\begin{array}{l}\text { Através da educação em saúde em grupos com enfermeiras notou-se } \\
\text { melhora na comunicação da gestante em suas relações. Seis semanas } \\
\text { pós-parto, 100\% já havia discutido contracepção com o parceiro; } \\
\text { tiveram maior controle sobre o uso do preservativo e conseguiram } \\
\text { revelar o diagnóstico para o parceiro. } \\
\text { Três meses após o parto, as mulheres apresentaram maiores escores de } \\
\text { conhecimento sobre o Dispositivo Intrauterino (DIU), de poder nos } \\
\text { relacionamentos; de controle do uso do preservativo; de probabilidade } \\
\text { de revelar o diagnóstico de HIV para o parceiro e maior probabilidade } \\
\text { de manter o relacionamento. Isso foi conseguido. }\end{array}$ & $\begin{array}{l}\text { A intervenção foi realizada a partir de } \\
\text { discussões em grupos focais no pré-natal e foi } \\
\text { possível dissipar equívocos em relação a } \\
\text { implantes de DIU e melhorar a habilidade de } \\
\text { comunicação e negociação com o parceiro. }\end{array}$ \\
\hline $\begin{array}{l}\text { The role of trust and health } \\
\text { literacy in nurse-delivered } \\
\text { point-of- care STI testing } \\
\text { for pregnant women living } \\
\text { with HIV, Tshwane } \\
\text { District, South Africa } \\
\text { (Medina-Marino et al., } \\
2020 \text { ) }\end{array}$ & $\begin{array}{l}\text { África do } \\
\text { Sul, } 2020\end{array}$ & $\begin{array}{ll}\text { Avaliar } & \text { a } \\
\text { aceitabilidade } & \mathrm{e} \\
\text { a viabilidade de } \\
\text { um programa de } \\
\text { diagnósticos de } \\
\text { ISTs }\end{array}$ & $\begin{array}{c}28 \\
\text { gestantes } \\
\text { com HIV }\end{array}$ & $\begin{array}{l}\text { Estudo } \\
\text { qualitativo }\end{array}$ & $\begin{array}{l}\text { O comportamento do enfermeiro foi associado à adesão e confiança no } \\
\text { processo de testagem, diagnóstico e tratamento, ou seja, durante os } \\
\text { atendimentos individuais a essas mulheres, principalmente no } \\
\text { primeiro. O apoio/aconselhamento reduziu o estresse da gestante e } \\
\text { aumentou o processo de construção da habilidade de comunicação } \\
\text { entre a gestante e seu parceiro. A relação de confiança entre gestante e } \\
\text { enfermeiro, estabelecida por meio da comunicação fundamentada na } \\
\text { escuta, no diálogo e sem julgamentos proporcionou um cuidado mais } \\
\text { amigável e empático e foi positivo em detrimento a experiências } \\
\text { negativas prévias. }\end{array}$ & $\begin{array}{l}\text { O estudo ressalta a importância da } \\
\text { comunicação entre o profissional e a gestante } \\
\text { para adesão e destaca o importante papel do } \\
\text { enfermeiro neste processo. }\end{array}$ \\
\hline $\begin{array}{l}\text { Factors related to medical } \\
\text { appointment attendance } \\
\text { after childbirth among } \\
\text { HIV-infected women in } \\
\text { the Paris region (Lemly et } \\
\text { al., 2007) }\end{array}$ & $\begin{array}{l}\text { França, } \\
2007\end{array}$ & $\begin{array}{l}\text { Avaliar fatores } \\
\text { associados à } \\
\text { adesão rà } \\
\text { consulta de } \\
\text { infectologia } \\
\text { após o parto nas } \\
\text { mulheres que } \\
\text { tiveram HIV na } \\
\text { gestação }\end{array}$ & $\begin{array}{c}169 \\
\text { puérperas }\end{array}$ & $\begin{array}{l}\text { Coorte } \\
\text { observacional }\end{array}$ & $\begin{array}{l}\text { O agendamento mais frequente de consultas durante o pré-natal, da } \\
\text { gestante com HIV, promove o aumento da comunicação entre o } \\
\text { profissional de saúde e ela, o que pode aumentar a frequência às } \\
\text { consultas após o parto. Além disso, evidenciou-se que apenas uma } \\
\text { criança testou positivo para HIV aos dois anos. Ter outra gestação no } \\
\text { intervalo de } 24 \text { meses foi um fator de confusão e } 21 \% \text { das mulheres } \\
\text { engravidaram novamente neste intervalo. Fazer uso de ARV aumentou } \\
\text { em } 13 \text { vezes a adesão e, a adesão ao pré-natal aumentou em duas vezes } \\
\text { a chance do seguimento regular. }\end{array}$ & $\begin{array}{l}\text { Aponta-se que o pré-natal é a janela para o } \\
\text { diagnóstico e tratamento da infecção pelo HIV. } \\
\text { Ressalta-se a necessidade de investigar faltosas } \\
\text { e motivos. Sugere-se agendar consultas de } \\
\text { infectologia durante o pré-natal para manter } \\
\text { vínculo após o parto. Desta forma, constata-se } \\
\text { a necessidade de ajustes e de boa comunicação } \\
\text { da gestante HIV positivo com a equipe. }\end{array}$ \\
\hline
\end{tabular}


Research, Society and Development, v. 10, n. 10, e574101019003, 2021

(CC BY 4.0) | ISSN 2525-3409 | DOI: http://dx.doi.org/10.33448/rsd-v10i10.19003

\begin{tabular}{|c|c|c|c|c|c|c|}
\hline 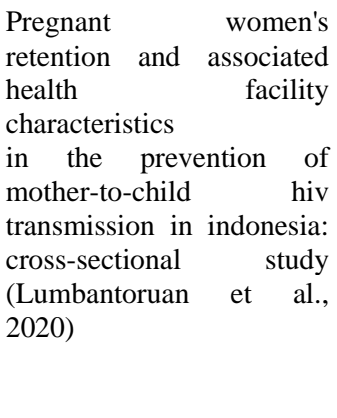 & $\begin{array}{c}\text { Indonésia, } \\
2020\end{array}$ & $\begin{array}{l}\text { Descrever a } \\
\text { adesão } \\
\text { mulheres de } \\
\text { programa de } \\
\text { redução } \quad \text { da } \\
\text { transmissão } \\
\text { vertical do HIV } \\
\text { na Indonésia e a } \\
\text { caracterização } \\
\text { das unidades de } \\
\text { saúde }\end{array}$ & $\begin{array}{c}6502 \\
\text { gestantes } \\
\text { com HIV }\end{array}$ & Transversal & $\begin{array}{l}\text { A comunicação, entre o profissional de saúde e a mulher com HIV, foi } \\
\text { fundamental para garantir a maior adesão dessas mulheres. Notou- se: } \\
\text { - } 57 \% \text { de adesão ao programa associado ao tratamento com ARV; } \\
\text { - Mulheres que eram assistidas em ambulatórios de } \\
\text { hospitais/maternidades, tinham } 2,88 \text { vezes mais chances de } \\
\text { permanecer; } \\
\text { - Serviços especializados em HIV na gestação tinham maior retenção; } \\
\text { Por isso, as estratégias de comunicação utilizadas nestes hospitais } \\
\text { especializados devem ser replicadas em todos os níveis de atenção a } \\
\text { este público-alvo. }\end{array}$ & $\begin{array}{l}\text { O estudo constatou que mulheres com piores } \\
\text { resultados de carga viral (justificado pelo uso } \\
\text { de TARV) e que demandaram cuidados com } \\
\text { especialistas, foram as que mais aderiram ao } \\
\text { programa. Reforça-se a importância de ter } \\
\text { especialistas na equipe para uma melhor } \\
\text { comunicação e, consequentemente, maior } \\
\text { adesão. }\end{array}$ \\
\hline $\begin{array}{l}\text { Knowledge, perceptions } \\
\text { and practices of HIV- } \\
\text { infected mothers regarding } \\
\text { HIV and infant } \\
\text { feeding, South African } \\
\text { (Robb et al., 2018). }\end{array}$ & $\begin{array}{l}\text { África do } \\
\text { Sul, } 2018\end{array}$ & $\begin{array}{l}\text { Avaliar o } \\
\text { conhecimento, } \\
\text { percepção e } \\
\text { práticas de mães } \\
\text { com HIV+ sobre } \\
\text { o vírus e a } \\
\text { alimentação } \\
\text { infantil }\end{array}$ & $\begin{array}{c}100 \\
\text { puérperas }\end{array}$ & Transversal & $\begin{array}{l}\text { O estudo apontou a necessidade de comunicação e aconselhamento de } \\
\text { qualidade para as mulheres durante a gestação para diminuir o risco de } \\
\text { transmissão vertical pelo aleitamento materno e com isso, façam } \\
\text { escolhas seguras. Embora as recomendações da OMS sejam de } \\
\text { aleitamento artificial para filhos de mães com HIV, recomenda-se que } \\
\text { seja uma alternativa AFASS (aceitável, viável, acessível, sustentável e } \\
\text { segura), tendo que ser assegurada fonte de água potável. Porém, menos } \\
\text { da metade possuía água potável. } \\
\text { Em casos de vulnerabilidade social, o aleitamento artificial pode ser } \\
\text { perigoso para a saúde da criança. }\end{array}$ & $\begin{array}{l}\text { Os conhecimentos, percepções e práticas } \\
\text { relacionados à alimentação infantil foram } \\
\text { inadequados. Fornecer informações com base } \\
\text { cientifica é essencial durante o aconselhamento } \\
\text { sobre alimentação infantil para que os } \\
\text { programas de prevenção de transmissão } \\
\text { vertical sejam eficazes. Evidencia-se a } \\
\text { necessidade de aconselhamento e comunicação } \\
\text { entre profissional e a gestante, de boa } \\
\text { qualidade para escolhas seguras. }\end{array}$ \\
\hline
\end{tabular}

Fonte: Autores. 
A análise dos artigos possibilitou verificar a amplitude e complexidade da comunicação de profissionais de saúde junto à gestante que vivem com HIV, na assistência pré-natal. Embora com objetivos e delineamentos diferentes, constatou-se, em todos os estudos, o impacto positivo da comunicação dos referidos profissionais com as gestantes. Evidenciou-se a influência positiva dos profissionais ao treinarem as gestantes para melhor comunicação com seus parceiros sobre: negociação sexual, o seu diagnóstico; conhecimento e reconhecimento dos métodos de planejamento familiar, assim como, no reconhecimento da vulnerabilidade social a que estão expostas.

A maioria dos estudos foi desenvolvida na África do Sul (Lemly et al., 2007; Lumbantoruan et al., 2020; MedinaMarino et al., 2020; Robb et al., 2018; Sarnquist et al., 2014). Isso pode ser justificado pelo fato do país, desde o início da pandemia de Aids na década de 80, apresentar maiores índices de morte e doenças pelo HIV, intensificando a crise política que o país enfrentava pelas lutas contra o Apartheid, do qual a população negra lutava pelo fim da discriminação social, econômica e política em que vivia (Barbosa Filho \& Vieira, 2019).

Sabe-se que a maioria das gestantes com HIV vivem em condições de vulnerabilidade social (Lemly et al., 2007; Lumbantoruan et al., 2020; Medina-Marino et al., 2020; Robb et al., 2018; Sarnquist et al., 2014). Esta vulnerabilidade deve ser entendida na perspectiva contextual do indivíduo, observando-se todos os fatores de risco que o envolvem, englobando questões sociais, econômicas e culturais. Nestes casos, em especial, é fundamental investigar o que levou essa mulher a estar inserida em uma situação de vulnerabilidade e a influência do diagnóstico do HIV/aids neste contexto (Soares et al., 2017).

Ressalta-se que o contexto socioeconômico pode impactar diretamente nos índices de transmissão vertical pelo aleitamento materno. A substituição pela fórmula láctea infantil (aleitamento artificial) é recomendada para reduzir este risco, mas frente ao panorama de vulnerabilidade social, isto se revela como um desafio em Joanesburgo, África do Sul (Robb et al., 2018). Para o estabelecimento do aleitamento artificial seguro é necessário o atendimento de alguns critérios como ter acesso à fórmula, à água potável, ao saneamento básico para ser preparada nas condições adequadas, a fim de que seja fornecido ao bebê a quantidade e qualidade do leite suficientes para promover o seu crescimento saudável. Por outro lado, essas condições ideais não fazem parte da realidade da maioria dessas mães e crianças.

Diante de casos de extrema vulnerabilidade social, nos quais os riscos contraindicam os benefícios do aleitamento artificial (Alvarenga et al., 2019), a OMS recomenda que o aleitamento artificial seja estabelecido caso apresente-se como uma alternativa AFASS, tendo que ser assegurada fonte de água potável, caso não possua, o aleitamento materno pode ser uma alternativa para mães com HIV (World Health Organization, 2016). Evidencia-se a necessidade de comunicação entre profissionais de saúde e gestantes que vivem com HIV desde o pré-natal para entender o contexto social e a vulnerabilidade em que ela está exposta, e consequentemente, entender seu contexto de vida no pós-parto. Esta comunicação deve ser baseada em uma avaliação rigorosa e criteriosa, para que a gestante seja informada e opte pela alternativa mais segura no seu caso. No Brasil, a oferta da fórmula até os seis meses de vida do lactente é garantida por lei, mas a literatura relata casos em que as mães não foram orientadas sobre tal e não receberam a fórmula (Alvarenga et al., 2019; Brasil, 2002).

Identificou-se que o baixo grau de escolaridade foi variável frequente em grande parte das amostras inclusas nos artigos (Lemly et al., 2007; Lumbantoruan et al., 2020; Medina-Marino et al., 2020; Robb et al., 2018; Sarnquist et al., 2014). De acordo com a literatura, tal variável influencia no aumento de pessoas contaminadas com HIV, uma vez que pode existir maior limitação na compreensão das informações transmitidas pelos profissionais de saúde, além de maiores dificuldades no acesso aos serviços. Estudos mostram que quanto maior o grau de escolaridade da gestante maior a sua adesão aos tratamentos necessários e ao pré-natal por assimilar melhor as informações recebidas (Pacheco et al., 2020). A compreensão dos riscos é imprescindível para a reflexão sobre a adoção ou não de medidas preventivas e negociação nas relações sexuais (Trindade et al., 2021). 
Estabelecer uma comunicação efetiva verbal e não verbal é indispensável para proporcionar atendimento de qualidade. Deve-se ter uma linguagem clara e acessível que envolva a mulher em sua totalidade e não apenas focada na gestação (Biasibetti et al., 2019). Este dado se confirma quando se avalia a adesão ao tratamento materno após o parto e o seguimento de puericultura, que apresentam grande relação de disparidade quando comparados.

Estes achados trazem à tona a necessidade de acolhimento e de comunicação adequada e terapêutica, com cuidado e qualidade, uma vez que o contrário pode gerar consequências negativas na vida da mulher e de seu filho. O profissional precisa saber ouvir, ter escuta ativa, estar atento ao que lhe é dito e, ao mesmo tempo, perceber o que está implícito nas falas dessas mulheres, ou seja, nas entrelinhas (Silva et al., 2019). É preciso também a utilização da comunicação não verbal, por ser essencial para a relação entre a gestante e o profissional na promoção e qualidade de saúde (Jamarim et al., 2019).

Ressalta-se que a forma de acolher interfere diretamente na adesão ao tratamento e nas escolhas destas gestantes, por isso o Programa Nacional de Infecções Sexualmente Transmissível (IST)/Aids/HIV enfatiza o acolhimento fundamentado no apoio emocional, educativo e na avaliação/feedback (Silva et al., 2019). Estudos (Medina-Marino et al., 2020; Sarnquist et al., 2014) destacaram a importância da presença do enfermeiro nestas relações e no desenvolvimento de habilidades de comunicação destas mulheres.

Por fim, salienta-se que a Aids ainda é uma doença estigmatizada. Possuir sorologia conhecida para HIV gera angústias e medo de conversar sobre o diagnóstico com o parceiro e familiares, principalmente pelo receio do julgamento social. Os estudos analisados revelam que por esta vulnerabilidade, muitas mulheres escondem o diagnóstico e optam pela não adesão ao tratamento (Lemly et al., 2007; Lumbantoruan et al., 2020; Medina-Marino et al., 2020; Robb et al., 2018; Sarnquist et al., 2014). Necessário considerar o intenso sofrimento que pode gerar na gestante, que muitas vezes, como os estudos apontam, recebe o diagnóstico junto com a confirmação da gestação e, associado a isso, tem-se a exacerbação dos sentimentos negativos e o pânico intenso diante do risco de contaminar o bebê (Bastos, 2019).

Estes fatos reforçam a necessidade urgente do acolhimento e da comunicação terapêutica diante de um problema multifatorial e complexo, como a experiência de gestar com HIV. A escuta ativa, sem julgamentos e a habilidade de comunicação dos profissionais de saúde junto à gestante com HIV precisam ocorrer durante a assistência pré-natal para proporcionar gestações e nascimentos mais seguros, além de uma experiência positiva na vida destas mulheres.

\section{Conclusão}

A comunicação entre os profissionais de saúde junto às gestantes que vive com HIV apresenta-se como uma potente ferramenta para um cuidado integral e justo, sendo uma oportunidade para que elas superem os desafios e se permitam vivenciar a gestação de maneira mais plena e com o mínimo de sofrimento. Esta comunicação efetiva e de qualidade impacta positivamente na saúde e na vida da gestante e, inclusive, influencia diretamente na sua adesão ao tratamento, no conhecimento de habilidades e possibilidades, nas escolhas seguras e no empoderamento feminino além de assegurar uma saúde mais integral para o bebê.

Como limitação, a escassez de estudos sobre o tema e o pequeno número amostral incluso na amostra desta revisão, demonstram lacunas na produção científica no que tange a comunicação da equipe de saúde junto a gestantes com HIV, na assistência pré-natal. Dada a magnitude do HIV na gestação e o alto risco de transmissão vertical e seus impactos negativos na vida das mães e crianças, sugere-se a ampliação de estudos, debates e divulgação sobre a temática. Destaca-se a necessidade de estudos futuros que utilizem a Técnica do Incidente Crítico para investigar, com base em situações reais vivenciadas no cotidiano dos serviços de saúde, a comunicação entre profissionais e gestantes com HIV, com vistas a contribuir para uma assistência dialógica, justa e equânime. 


\section{Referências}

Alvarenga, W. A., Nascimento, L. C., Leal, C. L., Fabbro, M. R. C., Bussadori, J. C. C., Melo, S. S.S., Cartagena-Ramos, D., \& Dupas, G. (2019). Mothers living with HIV: replacing breastfeeding by infant formula. Revista Brasileira de Enfermagem, 72(5), 1153-1160.

Bastos, R. A. (2019). Fases psicológicas de gestantes com HIV: estudo qualitativo em hospital. Revista Bioética, 17(2), 281-288.

Biasibetti, C., Hoffmann, L. M., Rodrigues, F. A., Wegner, W., \& Rocha, P.K. (2019). Comunicação para a segurança do paciente em internações pediátricas. Revista Gaúcha de Enfermagem, 40(esp), e20180337. 10.1590/1983-1447.2019.20180337

Brasil. (2021). Casos de Aids identificados no Brasil, por transmissão vertical, no período de 1985 a 2020. DATASUS.

Brasil (2020). Ministério da Saúde. Boletim epidemiológico de HIV e Aids. Número especial. 2020.

Brasil. (2002). Ministério da Saúde. Gabinete do Ministro. Portaria No 2313/GM em 19 de dezembro de 2002. Diário da União.

Barbosa Filho, E. A., \& Vieira, A. C. S. (2019). A (des)proteção social aos soropositivos na África do Sul pós-apartheid: da segregação racial ao minimalismo neoliberal. O Social em Questão, 22(45), 35-56.

Jamarim, M. F. M., Silva, C. Z., Lima, G. M. P. A., Siqueira, C. L., \& Campos, C. J. G. (2019). Nonverbal communication through touch: meanings for physical therapists working in a hospital environment. Aquichan, 19(4), e1942.

Joanna Briggs Institute. (2014). Reviewers' Manual 2014 Edition. Adelaide: The University of Adelaide.

Lemly, D., Mandelbrot, L., Meier, F., Firtion, G., Matheron, S., Jeantils, V., \& Scott, T. A. (2007). Factors related to medical appointment attendance after childbirth among HIV-infected women in the Paris region. AIDS Care, 19(3), 346-354.

Lobo, A. S., Leal, M.AF. (2019). Comunicação de más notícias: a revelação do diagnóstico de HIV/Aids e seus impactos psicológicos. Investigação Qualitativa em Saúde, volume 2.

Lumbantoruan, C., Kelaher, M., Kermode, M., \& Budihastuti, E. (2020). Pregnant women's retention and associated health facility characteristics in the prevention of mother-to-child HIV transmission in Indonesia: cross-sectional study. BMJ Open, 10(9), e034418.

Medina-Marino, A., Glockner, K., Grew, E., De Vos, L., Olivier, D., Klausner, J., \& Daniels, J. (2020). The role of trust and health literacy in nurse-delivered point-of- care STI testing for pregnant women living with HIV, Tshwane District, South Africa. BMC Public Health, $20,577$.

Moher, D., Liberati, A., Tetzlaff, J., Altman, D. G., \& The PRISMA Group. (2009). Preferred reporting items for systematic reviews and meta-analyses: the PRISMA statement. PloS Medicine, 6(7), e1000097.

Pacheco, K. T. S., Sakugawa, K. O., Martinelli, K. G., Esposti, C. D. D., Pacheco Filho, A. C., Garbin, C. A. S., Garbin, A. J. I., \& Santos Neto, E. T. (2020). Oral health and quality of life of pregnant women: the influence of sociodemographic factors. Ciência \& Saúde Coletiva, 25(6), $2315-2324$.

Pontes, B. S., Santos, A. K., Monteiro, S. (2020). Produção de discursos sobre a prevenção do HIV/Aids e da sífilis para gestantes em materiais educativos elaborados por instituições brasileiras (1995-2017). Interface Comunicação, Saúde, Educação, 24, e190559.

Robb, L., Walsh, C., \& Nel, M. (2018). Knowledge, perceptions and practices of HIV-infected mothers regarding HIV and infant feeding. South African Journal of Clinical Nutrition, 33(1), 23-29.

Sarnquist, C. C., Moyo, P., Stranix-Chibanda, L., Chipato, T., Kang, J. L., \& Maldonado, Y. A. (2014). Integrating family planning and prevention of mother to child HIV transmission in Zimbabwe. Contraception, 89(3), 209-214.

Silva, Y. T., Silva, L. B., \& Ferreira, S. M. S. (2019). Counseling practices in Sexually Transmitted Infections/AIDS: the female health professionals' perspective. Revista Brasileira de Enfermagem, 72(5), 1137-1144.

Soares, O. S., Silva, A. C. O., Silva, D. M., Freire, M. E. M., \& Nogueira, J. A. (2017). Prevalência e fatores de risco para o HIV/Aids em populações vulneráveis: uma revisão integrativa de literatura. Arquivo Catarinenses de Medicina, 46(4), 182-194.

Sousa, L. M. M., Vieira, C. A. M., Severino, S. S. P., \& Antunes, A. V. (2017). A metodologia de revisão integrativa da literatura em enfermagem. Revista Investigação em Enfermagem, 17-26.

Trindade, L. N. M., Nogueira, L. M. V., Rodrigues, I. L. A., Ferreira, A. M. R., Corrêa, G. M., \& Andrade, N. C. O. (2021). HIV infection in pregnant women and its challenges for the prenatal care. Revista Brasileira de Enfermagem, 74(Suppl 4), e20190784.

World Health Organization. (2016). Guideline: updates on HIV and infant feeding: duration of breastfeeding, and support from health services to improve feeding practices among mothers living with HIV.: WHO.

World Health Organization. (2021). Global HIV Programme. WHO. 